NBER WORKING PAPER SERIES

\title{
FIRM DYNAMICS, INVESTMENT, AND DEBT PORTFOLIO: BALANCE SHEET EFFECTS OF THE MEXICAN CRISIS OF 1994
}

\author{
Sangeeta Pratap \\ Carlos Urrutia \\ Working Paper 10523 \\ http://www.nber.org/papers/w10523
}

\section{NATIONAL BUREAU OF ECONOMIC RESEARCH 1050 Massachusetts Avenue Cambridge, MA 02138}

May 2004

We are grateful to Beatrix Paal, Raimundo Soto, Tim Kehoe, Satyajit Chatterjee, and participants at the 2003 IASE Seminar and the 2004 Midwest Macroeconomics Meetings for helpful comments. We are also grateful to Julio Burciaga and Jose Luis Negrin for help with the data and to Rainer Schwabe for excellent research assistance. We acknowledge the financial help of the Interamerican Development Bank in acquiring the data. The views expressed herein are those of the author(s) and not necessarily those of the National Bureau of Economic Research.

(C)2004 by Sangeeta Pratap and Carlos Urrutia. All rights reserved. Short sections of text, not to exceed two paragraphs, may be quoted without explicit permission provided that full credit, including (C) notice, is given to the source. 
Firm Dynamics, Investment, and Debt Portfolio:

Balance Sheet Effects of the Mexican Crisis of 1994

Sangeeta Pratap and Carlos Urrutia

NBER Working Paper No. 10523

May 2004

JEL No. C51, E22, E32, E5, G31

\section{ABSTRACT}

We build a partial equilibrium model of firm dynamics under exchange rate uncertainty. Firms face idiosyncratic productivity shocks and observe the current level of the real exchange rate each period. Given their current level of capital stock, firms make their export decisions and choose how much to invest. Investment is financed through one period loans from foreign lenders. The interest rate charged by each lender is set to satisfy an expected zero-profit condition. The model delivers a distribution of firms over productivity, capital stocks and debt portfolios, as well as an exit rule. We calibrate the model using data from a panel of Mexican firms, from 1989 to 2000, and analyze the effect of the 1994 crisis on these variables. As a result of the real exchange rate depreciation, the model predicts: (i) an increase in the debt burden, (ii) an increase in exports, and (iii) a large decline in investment. These real effects are consistent with the evidence for the Mexican crisis.

Sangeeta Pratap

Centro de Investigacion Economica

Instituto Tecnologico Autonomo de Mexico

Av. Camino Santa Teresa 930

10700, Mexico D.F.

Mexico

pratap@itam.mx

Carlos Urrutia

Centro de Investigacion Economica

Instituto Tecnologico Autonomo de Mexico

Av. Camino Santa Teresa 930

10700, Mexico D.F.

Mexico

currutia@itam.mx 


\section{Introduction}

In the past decade, several Latin American and East Asian countries have undergone currency crises that have been accompanied by substantial falls in investment and output. For instance, Mexico experienced in December 1994 a sudden real exchange rate depreciation of 55\%. The economy-wide GDP fell by more than $6 \%$ in 1995 and capital investment dropped by more than $29 \%$ in the same period.

Previous quantitative structural models have explained the fall in output and investment in terms of an exogenous drop in total factor productivity (see for example Bergoeing et al. 2002). However, given the large change in the relative price of domestic and foreign goods that was associated with these real effects, it is reasonable to expect that movements in the real exchange rate could have a role to play in explaining movements in investment and output.

The existing literature has identified two main channels through which exchange rate depreciations may affect investment. (See for example Krugman 1999). First, depreciations increase the competitiveness of firms in export markets and lead to higher export revenues. Second, firms that hold foreign currency denominated debt face an increase in the value of their liabilities in domestic goods. The former effect, termed the "competitiveness effect" increases profits and net worth, while the latter, termed the "balance sheet effect" reduces the net worth of firms. As the literature on the financial accelerator (see for example Bernanke and Gertler 1989) shows, in a world of imperfectly competitive capital markets, changes to the net worth affect firms' access to external funds and hence do have real effects. We could expect to find a positive or a negative effect of devaluation on investment and output, depending on the relative strengths of the two effects.

In this paper, we visit the same question, namely, how do depreciations affect firm investment. We build a model in which the which we can observe balance sheet and competitiveness effects. In addition, exchange rate movements also affect the cost of credit to firms in our model through two additional (opposing) channels. The interest rates charged to firms in foreign goods increase in the wake of a devaluation. This effect however, is mitigated by the fact that after a large depreciation, the expectation of subsequent devaluations is substantially smaller. This reduces the value of future expenditures (including debt repayments) in domestic goods. The net effect of devaluations on the cost of credit then depends on which of these effects dominate. We are therefore able to examine the effects of real exchange rate movements on firms' net worth and cost of credit in a unified framework and quantify their effect on output, investment and debt.

The model is a partial equilibrium model of a small open economy with heterogeneous firms. There are two goods: a domestic and a foreign good. The relative price of these two goods is the real exchange rate, that we assume follows an exogenously given first order Markov process. Firms produce domestic output using capital through a decreasing returns technology. Domestic output can be transformed into 
exports through a concave technology. In this way, we introduce in a simple way the insight that firms cannot switch their production from domestic markets to exports costlessly, due to, for example, an inelastic world demand for exports.

Firms accumulate capital over time. However, investment can only be financed through internal resources or by borrowing in the international capital market. Domestic borrowing and equity issue are not important sources of funds for firms in underdeveloped countries, because of participation constraints and/or high transaction costs. ${ }^{1}$ Therefore, we abstract from these sources of financing. Foreign debt is denominated in units of the foreign good. In case of default, the foreign lender seizes the current value of firm' resources. The interest rate is firm specific, and equal to the exogenous risk free rate adjusted for a risk premium. Competition among lenders drives expected profits to zero. ${ }^{2}$

Firms are heterogenous in their productivity, capital stock, and foreign debt. Individual firms' productivity follows a first order Markov process. In the aggregate, however, the only uncertainty is about the real exchange rate. Firms face an exogenous death (turnover) probability each period which, together with firms defaulting on their loans, generates exit in our model. Entry is exogenous, as new firms replace those who exit. We focus on an invariant distribution of firms across states.

To calibrate the model, we use a panel of Mexican firms participating in the stock market, between 1989 and 1994. These firms accounted for $80 \%$ of private borrowing before the 1994-95 crisis. In this sense, it is a special sample for which we should expect strong effects of the real exchange rate depreciation. We use individual firm's data on capital, sales, and exports to construct the idiosyncratic productivity processes. We then calibrate the key parameters so that the invariant distribution of our model replicates some aggregate moments (as capital to sales, investment to sales, exports to sales, debt to exports ratios, and exit rate) for these firms averaging the 1989-94 period.

The model delivers some predictions which are supported by the data. The debt contract implies that larger firms get better and cheaper access to foreign credit, which was the case prior to the 1994-95 crisis. The model also predicts a positive correlation between foreign debt and exports, and between capital and exports. At least qualitatively, this is also what we observe in our sample of firms. The model has also some limitations. We assume that investment and domestic output are the same commodity, abstracting from imports of capital goods. Therefore, we omit a potentially important channel through which a real depreciation affects investment,

\footnotetext{
${ }^{1}$ Dollar denominated debt as a proportion of total debt for our sample of Mexican firms has ranged between $60 \%$ and $70 \%$ since 1993 . In the same period, issuance of fresh equity for these firms ranged between only $0.2 \%$ and $0.4 \%$ of the outstanding stock of bonds plus equity.

${ }^{2}$ The model of firm dynamics that we use borrows from to Cooley and Quadrini (2001) and Pratap and Rendon (2003). In both models firm dynamics are determined by a combination of financial frictions and idiosyncratic productivity shocks. The present model differs from these models in that we also have an aggregate shock to exchange rates which affects net worth through its effect on exports, debt liabilities and the cost of credit.
} 
this is, through changes in the relative price of investment. ${ }^{3}$ Unfortunately, our panel data does not include information on imports at a firm level. Due to the same data limitation, we do not include labor and intermediate goods in the production function.

As an application, we use our quantitative model to analyze the effects of the 1994-95 Mexican devaluation. We feed our calibrated model with the actual path for real exchange rates between 1995-99 and analyze the response of firms to this sequence of aggregate shocks. The results of our experiment are consistent with: (i) an increase in the debt burden, (ii) an increase in exports, and (iii) a decline in investment, immediately after the devaluation. In fact, we account for $85 \%$ of the observed drop in investment in 1995 with our model. However, we are not able to account for the sustained export boom in the second half of the 1990s, which can probably be attributed to structural changes in the economy such as NAFTA, and the fast recovery of investment. ${ }^{4}$

A growing body of theoretical literature on currency crises stresses shocks to firm balance sheets as propagation mechanisms, such as Caballero and Krishnamurthy (2001), Aghion, Bacchetta and Banerjee (2000) and Schneider and Tornell (2001). There is also some empirical literature on the evidence of a balance sheet effect on investment. Bleakley and Cowan (2002) find in a cross section of countries that firms holding dollar denominated debt invest more than firms that do not, in other words, competitiveness effects outweigh the balance sheet effect. The same panel of Mexican firms participating in the stock market that we use in this paper has been used previously to estimate balance sheet effects on investment. Aguiar (2002) looks at the immediate effect of the crisis on investment and currency composition of debt in 1995 in Mexico. He finds that investment was positively related to net worth, which in turn was adversely affected by the holding of dollar debt in this year. Tornell, Westerman and Martinez (2004) find a positive relation between cash flow and investment after the 1994-95 crisis, suggesting the existence of liquidity constraints. They also report a larger decline in investment for non-tradable firms. Pratap et. al. (2003) find that after 1994, exporters invested more than non exporters, and that firms that held debt in dollars invested less than firms that did not hold dollar debt from 1994 to 1996. However, to the extent that investment, export and borrowing decisions are all made simultaneously, it is not clear that the effects identified in these papers can be considered causal.

\footnotetext{
${ }^{3} \mathrm{~A}$ rough estimate using aggregate data suggests that imports account for only $30 \%$ of total investment. Moreover, the relative price of investment increased by only $13 \%$ after the 1994-95 devaluation, compared to a $54 \%$ depreciation of the real exchange rate. This suggests that the effect of the real exchange rate depreciation on the relative price of investment is small.

${ }^{4}$ Another reason why the export boom is transitory in our model is because the decision rule for exports is static. Since firms decide period by period how to allocate production between the domestic and the foreign market, the appreciation of the real exchange rate after 1995 implies a sharp decline in exports. Adding a fixed cost of accessing foreign markets, or an export specific production factor which can be accumulated over time, would allow the model to generate a more persistent increase in exports. This is an interesting extension for future research.
} 
The paper is organized as follows: The next section sets out some features of the data that we seek to understand. Section 3 describes the model economy. In Section 4, we characterize some properties of the solution. In particular, we show how the interest rate charged by foreign lenders depends on firm's characteristics. In Section 5 we calibrate the model to match some features of the Mexican economy between 1989 and 1994. Section 6 shows the results of the 1994-95 devaluation experiment. The last section concludes.

\section{Data}

The data used in this study consists of the balance sheets and income statements of all firms listed in the Mexican stock market (Bolsa Mexicana de Valores or BMV). The data is at a yearly frequency and covers the period 1989 to 2000 . While the sample is restricted to publicly traded firms and firms that issue market debt, this does not represent a serious limitation for our study. First, this is the only data set of its kind available in Mexico and provides detailed information on the currency composition and maturity structure of debt. Second, while small firms that are not listed on the stock market could be exporters, they are not likely to have access to international capital markets. Our sample therefore, contains the firms where we are most likely to observe balance sheet effects of devaluations.

Each firm in the sample has an identifier, which allows us to link it across time. The panel is not balanced and we do observe entry and exit. Exit can take place if a firm is de-listed from the stock exchange, or if it merges with another one. In either case, the BMV removes the firm from the panel. However, we retain firms, which are de-listed in the panel for the entire period for which data is available.

Although the full sample includes 378 firms, only 339 firms were considered in the empirical analysis. This follows from the following adjustments. First, we removed firms with zero capital for one or more years. Second, we eliminated firms where the capital stock was beyond the mean +/- 3 standard deviations for any one year.

Table 1 presents the sectorial composition of the firms in our sample. Roughly half the firms are from the manufacturing sector and about $10 \%$ from construction. A third of the firms are in the service sector, which mainly comprises of trading and retail activities. There is also a handful of firms in transport and mining. About 15\% of the firms are not classified by sector and are grouped under the category "other".

The Pre-Crisis Scenario Table 2 shows some summary statistics from 1989 to 1994 and illustrates the properties of the sample in the years preceding the exchange rate crisis. The real exchange rate (pesos to dollar) is a series constructed by the Central Bank of Mexico. Firm level data is expressed in real terms, and measured in

pesos, deflated by the annual average producer price index (base year $=1994$ ) before the ratios were constructed. Capital stock was constructed by the perpetual inventory 
method using data on yearly investment expenditures. The book value of capital stock in the first period the firm appears was used to initialize the series. Short term debt refers to dollar denominated debt liabilities with a maturity period of up to a year. Total debt includes both short term and long term debt liabilities denominated in foreign currencies. The last column of the table shows the ratio of total interest payments to total short and long term liabilities, and is a measure of the cost of credit.

The real exchange rate appreciated steadily through this period as inflation increased and the nominal exchange rate remained stable. From a level of about 4.6 pesos to the dollar in 1990, it moved to 3.9 pesos in 1992 and stood at a high of 3.5 pesos to the dollar in 1994 before the devaluation in December. The capital-sales was relatively stable between 1990 and 1993 between 1.2 and 1.3, although it declined slightly in 1994. Exports were relatively modest in this period, and accounted for about $10 \%$ of total sales. The average investment to sales ratio in this period was about 13 per cent, however there was a 3\% increase in 1994, perhaps reflecting the positive expectations engendered by NAFTA.

Firms also undertook increasing amounts of debt in this period. The short term debt to exports ratio, which measures the ratio of foreign currency denominated outflows to inflows, ${ }^{5}$ increased dramatically through this period. From relatively moderate values of 0.7 in 1989, short term debt increased faster than exports and was more than 1.5 times the value of exports by 1993. Total liabilities in foreign currency were substantially more than double the level of exports in this period. This was paralleled by relatively low costs of credit, which are shown in the last column of Table 2. The ratio of interest payments to total liabilities was around 10 per cent up to 1992 and further declined to 7.6 percent by 1994. On the eve of the 1994 crisis therefore, these firms were experiencing a modest boom. Investment was rising, financed by increasing amounts of relatively cheap dollar debt. The strong exchange rate implied that exports accounted for a small proportion of sales and firms were very imperfectly hedged against exchange rate risk.

What were the characteristics of the firms that contracted these large and increasing amounts of debt? Tables 3 and 4 present some joint distributions for 1989 to 1994 . Both short and long term debt were strongly correlated with the amount of capital stock the firm owned. We also see that controlling for debt, larger firms also had lower financing costs. Similarly, controlling for capital, debt was positively related to financing costs. This suggests that large firms had cheaper and easier access to credit.

Exports and debt were also correlated positively. In fact, we see that firms that

\footnotetext{
${ }^{5}$ Of course firms may have other foreign currency inflows such as income from financial assets held abroad or other hedging devices. Information on the currency composition of financial assets is not available from the balance sheet. We also do not have information on any other foreign currency denominated outflows, such as imports of intermediate and capital goods. For the economy as a whole, expenditures on imported capital goods were about $30 \%$ of total expenditure on capital goods.
} 
borrowed more than the 75th percentile accounted for almost 90 per cent of exports and 74 percent of capital stock. Firms with zero debt tended to be very small both in terms of capital and sales. They also exported negligible amounts. ${ }^{6}$

The Effects of the 1994-95 Devaluation The exchange rate devalued sharply in December 1994. The real exchange rate of 1995 was 5.41 pesos to the dollar, almost 55 per cent higher than that of 1994, and remained well above 1994 levels up to for the next four years. This had large effects on firm behavior, as Table 5 shows. The value of foreign currency denominated debt in domestic goods shot up, and the short term debt to exports ratio increased from 1.5 to almost 1.8. This was accompanied by a substantial increase in the financing costs of liabilities, from 7 to 16 percent of the value of total liabilities, implying that even if firms had other investments for hedging exchange rate risk, the cost of credit increased substantially. These shocks to the balance sheet and to the cost of credit were reflected in the investment decisions of firm. The average investment to sales ratio fell by 5 percentage points by 1995 . Exports boomed, and doubled as a proportion of sales in the immediate aftermath of the devaluation. Despite this boom however, the debt to exports ratio declined only to 1.2 .

By 1996, firms made some efforts to align short term foreign currency denominated debt with exports. This ratio fell marginally below 1 in 1996, for the first time since 1989. In subsequent years the amount of short term debt undertaken by firms fell steadily till it was about 70 percent of total exports. This was accompanied by a corresponding decline in interest payments. Investment suffered from this lack of finance and did not recover till 1998.

Table 6 presents the changes in the absolute magnitudes of capital stock, debt, investment, exports and sales relative to 1994 values, which have been set to 100 . As was also shown in the previous table, the value of exports in real pesos doubled in 1995 and has remained at roughly that level since. Total sales in 1995 were practically stagnant, suggesting a large decline in domestic sales. Thereafter, total sales grew slower than exports. Domestic sales therefore, took a long time to recover. Short term debt in real pesos increased by 33 per cent in 1995, however it subsequently fell by about 20 percent in 1996 and a further 10 percent in the following year. Total debt liabilities also increased by 17 percent in the immediate aftermath of the exchange rate shock, and declined the following year.

Average investment declined by 40 percent in 1995 and remained below 1994 levels levels for four years. Table 7 shows how this decline in investment was distributed among firms with varying debt to exports ratios. It is striking that the largest fall in investment between 1989-1994 and 1995-2000 was for the firms that had low exports and high levels of debt. These firms reduced investment by 50 per cent. For firms with high levels of debt and exports, the fall was much more modest at about 11 per

\footnotetext{
${ }^{6}$ The reverse is not however true. Firms with zero exports accounted for more than $13 \%$ of total debt in the sample between 1989 and 1994.
} 
cent. It therefore seems that the fall in investment was related to the degree to which the firm could insulate itself against exchange rate shocks.

Finally Table 8 shows the relation between our sample and some macro aggregates. The firms in our sample accounted for about 12 to $15 \%$ of total investment in the economy (including government investment) in the years up to 1994. The total debt in foreign currency contracted by the firms in our sample was more than $80 \%$ of the total borrowing abroad by the private sector in the years around the exchange rate devaluation. Their exports however were just $18 \%$ of non-petroleum exports. The balance sheet effects for these firms can be expected to be more pronounced than for the economy as a whole. In fact, the total investment in the economy declined by $29 \%$, in 1994, however, these firms saw a substantially larger decline of about $38 \%$, since they were much more vulnerable to exchange rate risk.

We therefore need to build a model which captures the properties of our data described above. First, we need that larger firms are able to borrow more cheaply and in bigger amounts than smaller firms. We also need a model where firms whose exports are low relative to debt are the most vulnerable to large real depreciations. Finally our model must also capture the fact that interest rates are an increasing function of loan size and that devaluations increase the interest rate. In the next section we describe our model which exhibits all these features.

\section{The Model}

We build a partial equilibrium model of a small open economy with heterogeneous firms. There are two goods: a domestic and a foreign good. We denote the relative price of foreign over domestic goods (i.e., the real exchange rate) by $e$. This price is a random variable which follows a first order Markov process with support $[\underline{e}, \bar{e}]$ and conditional density $d F\left(e^{\prime} \mid e\right)$. A real depreciation of the domestic currency is equivalent to a high realization of $e$.

We model the domestic production sector as a continuum of firms heterogeneous in their level of capital $K$, their productivity, and their outstanding foreign debt $B$. We assume that firms face idiosyncratic productivity shocks $\theta$ each period, which also follow a first order Markov process with support $[\underline{\theta}, \bar{\theta}]$ and conditional density $d P\left(\theta^{\prime} \mid \theta\right)$.

Production and Exports At the beginning of each period, the real exchange rate $e$ and the idiosyncratic shock $\theta$ are realized. Given these realizations and the current values of $K$ firms produce $\theta f(K)$ units of domestic good, where $f$ is a concave production function. Firms also choose the fraction of their output $x$ devoted to exports given a concave technology to produce the foreign good out of the domestic 
good $\eta g[x \theta f(k)]$, where $\eta$ is a firm-specific export-type ${ }^{7}$. The export decision is static and independent of capital accumulation and its financing. The value of a firm's production in domestic goods (or total value of sales) is given by

$$
Y(K, e, \theta, \eta) \equiv \max _{x \in[0,1]}\{\operatorname{e\eta g}[x \theta f(K)]+(1-x) \theta f(K)\}
$$

The dynamics of the firm is governed by the investment decision and its financing. Given their capital $K$, outstanding foreign debt $B$, the real exchange rate $e$ and the current productivity $\theta$, firms choose their level of investment $I$, given the law of motion for firm's capital $K^{\prime}=(1-\delta) K+I$ and a depreciation rate $\delta$. Investment must be financed out of firms current resources (or net worth)

$$
W(K, R B, e, \theta, \eta) \equiv Y(K, e, \theta, \eta)+(1-\delta) K-e R B
$$

and new foreign borrowing $B^{\prime}$, subject to the non negative dividend constraint:

$$
Y(K, e, \theta, \eta)+(1-\delta) K-e R B+e B^{\prime}-K^{\prime} \geq 0
$$

where $R$ is the gross, firm specific interest rate measured in foreign goods.

Interest Rate on Loans The interest rates of loans are set before uncertainty at the period of repayment is realized. In case of default, foreign lenders have the right to seize all the firms resources and the firm must exit. Foreign lenders have access to an international credit market, with a risk-free interest rate $\rho$ given. Competition among lenders ensures that the firm specific interest rate would be equal to the risk free rate, adjusted for a risk premium, so as to satisfy a expected zero profit condition.

Consider the problem of the representative foreign lender. A loan of size $B^{\prime}$ will be repaid only if $W\left(K^{\prime}, R^{\prime} B^{\prime}, e^{\prime}, \theta^{\prime}, \eta^{\prime}\right) \geq 0$, that is, if the value of the firm's net worth tomorrow is non-negative. Otherwise, the firm is liquidated and the foreign lender seizes the value of firm's collateral

$$
\Pi(K, e, \theta, \eta) \equiv Y(K, e, \theta, \eta)+(1-\delta) K
$$

measured in units of domestic output. For simplicity, we rule out the possibility of renegotiating loans, i.e., the possibility to pay back current debt with new borrowing.

Competitive lending implies that the interest rate in foreign goods $R^{\prime}$ must satisfy the following zero-profit condition

$$
\pi R^{\prime} B^{\prime}+\int_{\Omega} \frac{\Pi\left(K^{\prime}, e^{\prime}, \theta^{\prime}, \eta\right)}{e^{\prime}} d P\left(\theta^{\prime} \mid \theta\right) d F\left(e^{\prime} \mid e\right)=(1+\rho) B^{\prime}
$$

\footnotetext{
${ }^{7}$ To have a well defined problem, we impose the following conditions on the production function $f$ : (i) $f(0)=0$; (ii) $f$ strictly increasing; (iii) $f$ strictly concave, and (iv) $f$ satisfies the Inada conditions: $\lim _{K \rightarrow 0} f^{\prime}(K)=+\infty$ and $\lim _{K \rightarrow+\infty} f^{\prime}(K)=0$. Similarly, we assume: (i) $g(0)=0$; (ii) $g$ strictly increasing; (iii) $g$ strictly concave, and (iv) $g$ satisfies the Inada conditions: $\lim _{y \rightarrow 0} g^{\prime}(y)=+\infty$ and $\lim _{y \rightarrow+\infty} g^{\prime}(y)=0$.
} 
where $\pi \equiv \operatorname{Pr}\left[\Pi\left(K^{\prime}, e^{\prime}, \theta^{\prime}, \eta\right) \geq e^{\prime} R^{\prime} B^{\prime}\right]$ is the probability of repayment and $\Omega \equiv$ $\left\{e^{\prime}, \theta^{\prime} \mid \Pi\left(K^{\prime}, e^{\prime}, \theta^{\prime}, \eta\right)<e^{\prime} R^{\prime} B^{\prime}\right\}$. This condition implicitly defines a firm specific interest rate $R^{\prime}\left(K^{\prime}, B^{\prime}, e, \theta, \eta\right)$ as a function of the firm's type, the real exchange rate, the size of the loan and the amount of capital accumulated for next period.

Bellman Equation for the Firm Let $\rho_{d}$ be the domestic interest rate used by firms to discount profits, and $\lambda$ an exogenous death (or turnover) probability. Define also the indicator function

$$
\Upsilon(K, R B, e, \theta, \eta)=\left\{\begin{array}{l}
1, \text { if } \Pi(K, e, \theta, \eta) \geq e R B \\
0, \text { otherwise }
\end{array}\right.
$$

which takes the value 1 whenever the firm is in a state in which the debt is repaid. The firm's dynamic optimization problem can now be written in recursive form as

$$
\begin{gathered}
V_{\eta}(K, R B, e, \theta)=\max _{\left\{K^{\prime}, B^{\prime}\right\}}\left\{Y(K, e, \theta, \eta)+(1-\delta) K-e R B+e B^{\prime}-K^{\prime}\right. \\
\left.+\left(\frac{1-\lambda}{1+\rho_{d}}\right) \int_{\underline{e}}^{\bar{e}} \int_{\underline{\theta}}^{\bar{\theta}} \Upsilon\left(K^{\prime}, R^{\prime} B^{\prime}, e^{\prime}, \theta^{\prime}, \eta\right) V_{\eta}\left(K^{\prime}, R^{\prime} B^{\prime}, e^{\prime}, \theta^{\prime}\right) d P\left(\theta^{\prime} \mid \theta\right) d F\left(e^{\prime} \mid e\right)\right\}
\end{gathered}
$$

subject to the conditions (1), (2), and (3). We also require $B^{\prime} \geq 0$, i.e., the firm cannot accumulate resources other than capital stock.

Aggregate Dynamics Each period, a fraction $\lambda$ of firms exit the economy, together with firms which default on their loans. We assume that these firms are replaced next period by a similar mass of firms with: (i) the minimum level of capital, (ii) a level of debt equal to a fixed cost of entry $\phi$, (iii) a random productivity draw, and (iv) same export-type.

Let the measure $\mu(K, R B, \theta, \eta)$ to represent the distribution of firms in the economy, so that the aggregate state for the economy is $(\mu, e)$. Given a current value for the real exchange rate $e$, the distribution of firms $\mu$ evolves according to the operator $T_{e}$, defined as $\mu^{\prime} \equiv T_{e} \mu$ where

$$
\begin{gathered}
\mu^{\prime}\left(K^{\prime}, R^{\prime} B^{\prime}, \theta^{\prime}, \eta\right)= \\
(1-\lambda) \int_{\Theta_{e}}\left\{P\left(\theta^{\prime} \mid \theta\right) \Upsilon(K, R B, e, \theta, \eta)\right\} d \mu(K, R B, \theta, \eta)
\end{gathered}
$$

using $\Upsilon$ as the indicator function defined above and

$$
\Theta_{e}=\left\{\begin{array}{l|l}
K, B, \theta, \eta & \begin{array}{c}
K^{\prime}(K, B, e, \theta, \eta)=K^{\prime} \\
B^{\prime}(K, B, e, \theta, \eta)=B^{\prime}
\end{array}
\end{array}\right\}
$$


The entry/exit rule implies

$$
\begin{gathered}
\mu^{\prime}\left(K_{\min }, e \phi, \theta^{\prime}, \eta\right)= \\
\int_{\Theta_{e}}\left\{P\left(\theta^{\prime} \mid \theta\right)[\lambda \Upsilon(K, R B, e, \theta, \eta)+(1-\Upsilon(K, R B, e, \theta, \eta))]\right\} d \mu(K, R B, \theta, \eta)
\end{gathered}
$$

By construction, it is the case that $\int_{K, R B, \theta, \eta} d \mu(K, R B, \theta, \eta)=1$, so $\mu$ is indeed a probability distribution function.

The distribution of firms allow us to compute aggregate statistics for the economy, given a real exchange rate $e$. For instance, aggregate output (or total value of sales) is given by

$$
\bar{Y}(\mu, e)=\int_{K, R B, \theta, \eta} Y(K, e, \theta, \eta) d \mu(K, R B, \theta, \eta)
$$

investment, by

$$
\bar{I}(\mu, e)=\int_{K, R B, \theta, \eta}\left[K^{\prime}(K, B, e, \theta, \eta)-(1-\delta) K\right] d \mu(K, R B, \theta, \eta)
$$

and exports, in units of domestic output,by

$$
\bar{X}(\mu, e)=e \int_{K, R B, \theta, \eta} \eta g[x(K, e, \theta, \eta) \theta f(K)] d \mu(K, R B, \theta, \eta)
$$

An invariant distribution for a constant real exchange rate $e$ is a distribution of firms $\mu^{*}$ satisfying $\mu^{*}=T_{e} \mu^{*}$. In our benchmark economy, we focus on an invariant distribution in which $e$ takes its mean value. This is, we look for the asymptotic distribution of firms shutting down the aggregate uncertainty in the economy.

\section{Characterizing Optimal Firm's Decisions}

We begin our analysis characterizing some properties of the firm's optimal decisions and the interest rates for loans. We explain these properties intuitively in the text and present a series of formal propositions with proofs in the Appendix.

\subsection{The Export Decision and Firm's Collateral}

The firm faces an export decision, i.e., has to decide the fraction of output $x$ devoted to the export market. This decision is static, since output is determined. The optimal export decision can be represented by a function $x(K, e, \theta, \eta) \in[0,1]$.

The optimal choice of $x$ can be understood from Figure 1, which shows the trade off between domestic and export production. Given $K, \theta$ and $\eta$, domestic goods can 
be transformed into exports through the concave technology $g($.$) . A unit decline in$ domestic output increases export output by $\eta g^{\prime}(x \theta f(K))$ For an interior solution, the relative price line, with slope $1 / e$, must be tangent to this production possibility frontier, i.e.

$$
\frac{1}{e}=\eta g^{\prime}(x \theta f(K))
$$

The solution to this equation gives us $x(K, e, \theta, \eta)$. As $e$ increases, exports become more profitable and $x$ increases. It is also easy to see that given $\theta, K$ and $e$, a firm with a higher $\eta$ will export a higher share of its output compared to a firm with a lower $\eta$. For the tangency condition to hold, a higher $\eta$ will require a lower $g^{\prime}(x \theta f(K))$ which can only be achieved with a higher $x$, given the concavity of $g(x \theta f(K))$. Similarly an increase in $K$ will increase domestic production more than it will increase exports, since domestic goods require a transformation of capital through the function $f($. whereas the production of exports necessitates a transformation of capital through $f($.$) and g($.$) . Hence an increase in K$ will reduce the share of exports in total production. A similar argument implies that, given $\eta$, higher $\theta$ firms will export a smaller share of their output.

Replacing the optimal export decision in the definition of firm's total resources today we obtain the indirect function

$$
\Pi(K, e, \theta, \eta) \equiv \operatorname{e\eta g}[x(K, e, \theta, \eta) \theta f(K)]+(1-x(K, e, \theta, \eta)) \theta f(K)+(1-\delta) K
$$

which represents the current value of firm's collateral in units of domestic output. This collateral function is increasing in $K$ and $\theta$. It is also increasing in $e$ and in the firm's export productivity $\eta$. These results are all proved in Proposition 2 in the appendix.

$\Pi(K, e, \theta, \eta) / e$ represents the value of firm's collateral in units of foreign output and can be written as

$$
\frac{\Pi(K, e, \theta, \eta)}{e} \equiv \eta g[x(K, e, \theta, \eta) \theta f(K)]+(1-x(K, e, \theta, \eta)) \frac{\theta f(K)}{e}+\frac{(1-\delta) K}{e}
$$

As $e$ increases, we know that exports increase and domestic production declines. However, we saw earlier, that the increase in exports is less than the decline in domestic production, given the concave export technology $g($.$) , so that \Pi(K, e, \theta, \eta) / e$ is declining in $e$. This is an important feature of our model since the value of resources in foreign goods is collateral for borrowing. A depreciation in the real exchange rate reduces the value of this collateral and reduces the capacity of firms to borrow. Given the financial market imperfections, this has real effects on investment. 


\subsection{The Equilibrium Interest Rate}

Consider a representative foreign intermediary lending $B^{\prime}$ units of foreign output at an interest rate $R^{\prime}$ to a firm with productivity $\theta$ and export-type $\eta$. The probability of repayment $\pi$ is defined as $\pi \equiv \operatorname{Pr}\left[\Pi\left(K^{\prime}, e^{\prime}, \theta^{\prime}, \eta\right) \geq e^{\prime} R^{\prime} B^{\prime}\right]$ where $e^{\prime}$ and $\theta^{\prime}$ are the realizations of the real exchange rate and the productivity shock tomorrow and $K^{\prime}$ is the firm's capital tomorrow. $K^{\prime}$ of course is the result of an optimal decision rule implemented today as a function of the state $(K, R B, e, \theta, \eta)$, which we take for now as given. We also define the conditional probability $\pi_{\theta^{\prime}} \equiv$ $\operatorname{Pr}\left[\Pi\left(K^{\prime}, e^{\prime}, \theta^{\prime}, \eta\right) \geq e^{\prime} R^{\prime} B^{\prime} \mid \theta^{\prime}\right]$, such that $\pi=\int_{\theta}^{\bar{\theta}} \pi_{\theta^{\prime}} d P\left(\theta^{\prime} \mid \theta\right)$.

The probability of repayment depends on the interest rate charged by the foreign lender, the optimal decisions $K^{\prime}, B^{\prime}$, and the realizations of $e^{\prime}$ and $\theta^{\prime}$. For this, let us define the cut-off value $\hat{e}\left(K^{\prime}, R^{\prime}, B^{\prime}, \theta^{\prime}, \eta\right)$ by

$$
\hat{e}\left(K^{\prime}, R^{\prime}, B^{\prime}, \theta^{\prime}, \eta\right) \equiv\left\{\begin{array}{l}
\bar{e}, \text { if } \Pi\left(K^{\prime}, \bar{e}, \theta^{\prime}, \eta\right) \geq \bar{e} R^{\prime} B^{\prime} \\
\underline{e}, \text { if } \Pi\left(K^{\prime}, \underline{e}, \theta^{\prime}, \eta\right) \leq \underline{e} R^{\prime} B^{\prime} \\
\left\{e^{\prime} \mid \Pi\left(K^{\prime}, e^{\prime}, \theta^{\prime}, \eta\right)=e^{\prime} R^{\prime} B^{\prime}\right\}, \text { otherwise }
\end{array}\right.
$$

The cut-off level $\hat{e}$ represents the maximum real exchange level for which the firm can honor the foreign debt contract. This level depends on the firm capital, debt, and productivity tomorrow. Above this level, the firm defaults and the foreign lender seizes all current collateral.

The probability of repayment, conditional on firm's productivity tomorrow, is given by

$$
\pi_{\theta^{\prime}}=\left\{\begin{array}{l}
1, \text { if } \widehat{e}=\bar{e} \\
0, \text { if } \widehat{e}=\underline{e} \\
F(\hat{e} \mid e) \in(0,1), \text { otherwise }
\end{array}\right.
$$

We can restate now the zero profit condition for the foreign lender (3) as

$$
\begin{gathered}
\Gamma\left(K^{\prime}, R^{\prime}, B^{\prime}, e, \theta, \eta\right) \equiv \\
\int_{\underline{\theta}}^{\bar{\theta}}\left\{\pi_{\theta^{\prime}} R^{\prime} B^{\prime}+\int_{\widehat{e}}^{\bar{e}} \frac{\Pi\left(K^{\prime}, e^{\prime}, \theta^{\prime}, \eta\right)}{e^{\prime}} d F\left(e^{\prime} \mid e\right)\right\} d P\left(\theta^{\prime} \mid \theta\right)-(1+\rho) B^{\prime}=0
\end{gathered}
$$

noting that both $\pi_{\theta^{\prime}}$ and $\widehat{e}$ are functions of $K^{\prime}, \theta^{\prime}, R^{\prime}, B^{\prime}$, and $e$. This condition implicitly defines $R^{\prime}$ as a function of $K^{\prime}, B^{\prime}, e, \theta$, and $\eta$.

Firms with higher capital stock tomorrow will obtain loans at a lower interest rate. The intuition for this is simple: A higher value of $K^{\prime}$ will imply that the firm has higher collateral tomorrow. Hence the cut off value of $e^{\prime}$ up to which it is able to pay its loans is higher, and the probability of default is lower, all other things remaining constant. Similarly, a high value of $\eta$, by increasing the value of collateral and reducing the risk of default, implies a lower interest rate. 
We can also show that for a given level of $K^{\prime}$, the interest rate is increasing in $B^{\prime}$. A higher $B^{\prime}$, all other things constant, will imply that the largest realization of the exchange rate $\widehat{e}$ at which the firm is able to pay its debt, is lower. This increases the probability of default and the lender charges a higher premium over the interest rate. Proposition 5 in the appendix formalizes these arguments.

The effect of the current interest rate $e$ on the interest rate works in two ways. Given $K^{\prime}$ and $B^{\prime}$ (which are themselves functions of $e$ ), ${ }^{8}$ a high value of $e$ today implies that the value of $e^{\prime}$ tomorrow will also be high, given the persistence of the process for the exchange rate. This will reduce the expected value of collateral tomorrow and therefore raise the probability of default. Second, a high value of $e$ will shift the density $f\left(e^{\prime} \mid e\right)$ to the right. For inverted $U$ shaped densities (including the normal and the log normal), this will increase the density for high realizations of $e^{\prime}$ and reduce it for low realizations of $e^{\prime}$. This implies that the probability of $e^{\prime}$ being below a cutoff $\widehat{e}$ is reduced, i.e there is a smaller probability of repayment. In Proposition 6 we provide conditions under which a depreciation of the real exchange rate increases/decreases the interest rate.

\subsection{Net Worth and Cost of Capital Effects}

We now summarize the results obtained so far, focusing on the different effects of a real depreciation affecting investment decisions. We divide these effects in two groups: net worth and cost of credit effects.

Net Worth Effects Firms' net worth is defined as total assets minus liabilities. In a given period, this is

$$
W(K, R B, e, \theta, \eta) \equiv Y(K, e, \theta, \eta)+(1-\delta) K-e R B
$$

From this definition, it is clear that the real exchange rate affects firms' net worth through two opposite channels. As we have seen earlier, a real depreciation $(e \uparrow)$ increases exports, and hence $\Pi(K, e, \theta, \eta)$ and net worth. We call this the competitiveness effect. On the other hand, the depreciation increases the burden of foreign debt in units of domestic output $(e R B)$, for a given interest rate decided in the previous period, reducing net worth. This is the balance sheet effect which has been stressed in the literature.

Since net worth determines the internal resources available to a firm, the impact of a depreciation on investment depends (everything else equal) on the relative importance of these two effects. A strong competitiveness effect would imply a positive relation between the real exchange rate and investment, while a strong balance sheet effect would have the opposite implication.

\footnotetext{
${ }^{8}$ In this sense we are concerned with the direct effect of $e$ on the interest rate, not the indirect effects through changes in $K^{\prime}$ and $B^{\prime}$.
} 
The relative strengths of these two effects are illustrated in Figure 2. The solid line shows $\Pi(K, e, \theta, \eta)$ as a function of $e$ and the various dashed lines denote different levels of $e R B$. The solid line is convex in $e$ until the point $x=1$. The intuition for this is the same as the intuition for the convexity of a profit function in prices. As $e$ increases, if the firm does not change its export decision, $x, \Pi(K, e, \theta, \eta)$ would increase linearly. However, since the firm will re-optimize its export decision following a change in $e$, the increase in $\Pi(K, e, \theta, \eta)$ is larger, leading to the convex shape that we observe. When $e$ is high enough and $x=1$, the firm cannot increase exports any more, and the value of its resources can only increase linearly with further increases in $e$. The net effects of devaluation depend on the relative magnitudes of $\Pi(K, e, \theta, \eta)+(1-\delta) K$ and $e R B$. For highly indebted firms, the balance sheet effect always dominates, whereas for firms with low debt, the competitiveness effect is stronger. For firms with debt levels between these two extremes, the effect of devaluations depends on their magnitude. Moderate devaluations increase the value of resources, but very small or very large devaluations have a negative effect on net worth.

Cost of Credit Effects Firms finance their investment through their internal resources and borrowing abroad. Consider a firm borrowing $B^{\prime}$ units of the foreign good today. This operation provides the firm with $e B^{\prime}$ units of domestic output, which can be devoted to investment in capital goods. Tomorrow, the firm expects to repay $E\left[e^{\prime}\right] R^{\prime} B^{\prime}$ units of domestic output. The expected cost of this operation for the firm is

$$
\kappa\left(e, R^{\prime}\right) \equiv E\left[\frac{e^{\prime}}{e}\right] R^{\prime}
$$

where $E\left[\frac{e^{\prime}}{e}\right]$ is the expected devaluation rate. The cost of credit $\kappa\left(e, R^{\prime}\right)$ is affected by the real exchange rate through its effect on (i) the expected devaluation, and (ii) the interest rate in foreign goods. With a mean reverting process for $e$, a high realization today implies a low expected devaluation rate. Hence, a real depreciation decreases the cost of credit through this channel (Fisher effect). On the other hand, Proposition 6(i) in the appendix states conditions under which a high realization of $e$ increases the interest rate in foreign goods, increasing the cost of credit (interest rate effect). ${ }^{9}$

Again, the impact of a depreciation on the cost of credit and investment depends on the relative importance of these two effects. Keeping net worth fixed, a higher cost of credit (due to a strong interest rate effect) decreases investment, while a lower cost of credit (due to a strong Fisher effect) increases it.

\footnotetext{
${ }^{9}$ As discussed in the introduction, we abstract from changes in the relative price of investment, which also affects the cost of credit faced by firms.
} 


\section{A Quantitative Model Economy}

We calibrate the model in order to match some statistics from our sample of Mexican firms. For this, we make a strong assumption about stationarity, that is, we try to reproduce the properties of the 1989-94 panel of firms as if this panel was extracted from the invariant distribution of our model. As seen in Table 2, some key ratios remained relatively constant during the pre-devaluation period. However, the 198994 featured an appreciation of the real exchange rate, which is inconsistent with our stationarity assumption. We see this exercise as a first step in order to assess the effects of the 1994-95 devaluation.

\subsection{Calibration Strategy}

The main parameters of the model to be calibrated are $\alpha$, the technology parameter, $\xi$, the parameter for the transformation of domestic output into foreign output, $\delta$, the depreciation rate of capital, $\rho_{d}$, the domestic interest rate (or firm's discount factor), $\rho$, the risk free rate abroad, $\phi$, the fixed cost of entry, and $\lambda$, the exogenous turnover probability. In addition, we need to calibrate the process for $\theta$, the firm specific technology shock, the process for $e$, the exchange rate, and $\eta$ which is the idiosyncratic export-type of firms.

We choose an international risk free rate of $5 \%$, consistent with the average postwar US treasury bills rate, and a domestic interest rate of $13 \%$, equal to the average real return of Mexican treasury bonds (CETES) in the 1989-94 period. Given our partial equilibrium setup, the stochastic process for the real exchange rate is also calibrated outside the model. We restrict this process to follow the AR(1) process in $\log s$

$$
\log e_{t+1}=\bar{\mu}+\gamma \log e_{t}+\varepsilon_{t+1}
$$

where $\varepsilon_{t}$ is a white noise with variance $\sigma_{\varepsilon}^{2}$. Using annual data on the real exchange rate for Mexico between 1989-2002, we estimate $\bar{\mu}=0.35, \gamma=0.72$, and $\sigma_{\varepsilon}=0.145$. We then transformed it into a first order discrete Markov process using the Tauchen (1986) procedure, with a grid of 7 possible realization values. ${ }^{10}$

The calibration strategy for the remaining parameters implies a complicated fixed point problem. First, given initial values for $\alpha$ and $\xi$, we estimate the process for $\theta$ and $\eta$ using our sample of firms (the details are explained next). Second, given these processes, we choose the values of $\alpha, \xi, \delta, \phi$ and $\lambda$ so that the invariant distribution reproduces the 1989-94 averages of the capital to sales ratio, the investment to sales

\footnotetext{
${ }^{10}$ We use a CPI-based measure of the real multilateral (111 countries) exchange rate for Mexico. As a robustness check, we estimate the stochastic process for $\log e_{t}$ using a PPI-based real exchange rate for Mexico, which is only reported as a bilateral exchange rate with respect to the US. The resulting process features slightly less persistence and variabilty than using our original measure. However, the results of the numerical experiment do not change significantly.
} 
ratio, the exports to sales ratio, the foreign debt to exports ratio, and the exit rate observed in our sample of firms ${ }^{11}$. If the initial values of $\alpha$ and $\xi$ are different form those obtained at the second stage, we update them and start again.

\subsection{The Stochastic Process for Productivity and Export-types}

Our panel of firms provides the data for the capital to sales and exports to sale ratios, as well as the capital stock, for each firm and year between 1989-94. Given the (initial) values of $\alpha$ and $\xi$, and the real exchange rate for each year, we estimate the parameters $\theta_{i t}$ and $\eta_{i t}$, for each firm in each year solving simultaneously the system of equations

$$
\frac{\text { Capital }}{\text { Sales }}=\frac{K}{e \eta\left(x \theta K^{\alpha}\right)^{\xi}+(1-x) \theta K^{\alpha}}
$$

and

$$
\frac{\text { Exports }}{\text { Sales }}=\frac{e \eta\left(x \theta K^{\alpha}\right)^{\xi}}{e \eta\left(x \theta K^{\alpha}\right)^{\xi}+(1-x) \theta K^{\alpha}}
$$

where

$$
x=\max \left(0, \min \left(1, \frac{(e \eta \xi)^{\frac{1}{1-\xi}}}{\theta K^{\alpha}}\right)\right)
$$

is the optimal exports decision in the theoretical model.

Next, we take average values for $\theta$ and $\eta$ for each firm across the period 1989-94, and discretize these values into an equally log-spaced 5 point grid. The transition matrix for $\theta$ is calculated using the empirical distribution of the estimated values of $\theta$. In other words we counted the relative frequency of particular pair of $\left(\theta, \theta^{\prime}\right)$ in two consecutive time periods, for all 25 possible combinations of $\left(\theta, \theta^{\prime}\right)$ and for all time periods.

\subsection{Calibration Targets}

Given the stochastic processes, we choose the values of $\alpha, \xi, \delta, \phi$ and $\lambda$ so that the invariant distribution reproduces some 1989-94 statistics. To construct this invariant distribution, we solve the model by value function iteration. The steps are:

\footnotetext{
${ }^{11}$ These ratios are reported in Table 2 and discussed in the data section. Notice that, since debt in the data is reported at the end of the period, the calibration target consistent with our model is the average debt to exports ratio up to 1993 (or beginning of 1994), which is only 2.19. With respect to the exit rate, we compute the fraction of firms which exit our sample of firms between 1989-94, which is roughly $11 \%$. We are aware that this measure of turnover is problematic, since firms de-listed form the stock market might still be active.
} 
1. For each value of $\left(K^{\prime}, B^{\prime}, e, \theta, \eta\right)$ in the grids, we solve for the interest rate $R^{\prime}$ which satisfies the zero-profit condition for foreign lenders.

2. Given $R^{\prime}$, we solve the dynamic programming problem at each point in the grid for $(K, R B, e, \theta, \eta)$ using value function iteration. This gives us the policy rules $K^{\prime}$ and $B^{\prime}$.

3. Given these policy rules and the transition function for the distribution $\mu$, we fix the real exchange rate $e$ to its average level and iterate until obtaining an invariant distribution $\mu^{*}(\bar{e})$.

Table 9 presents the results of the exercise. We obtain a value for the capital share in the production function of 0.36 , which is close to the standard value obtained form calibration exercises using aggregate production functions (see, for instance, Bergoeing et. al., (2002)). We also obtain a depreciation rate of $11 \%$, which is similar to the depreciation rate constructed using estimates of capital stocks and depreciation for a sample of Mexican firms, mostly manufacturing. ${ }^{12}$ The implied value for the elasticity of exports to the real exchange rate $\left(\frac{1}{1-\xi}\right)$ is about 2.5 . We don't have independent estimates for this elasticity, although we believe our number is not unreasonable. Finally, we obtain a fixed cost of 55 and an exogenous turnover probability of $6 \%$, from which we do not have independent estimates either. Under this parametrization, the benchmark economy reproduces fairly well the statistics observed in the 1989-94 data. If anything, we slightly underpredict the amount of foreign debt in the model.

\subsection{Other Statistics}

In Table 10, we compare some additional properties of the invariant distribution of firms generated by the model to the 1989-94 data. In our benchmark economy capital, debt, exports and productivity $(\theta)$ are all positively correlated, which is also true in the data. However, we generate a smaller correlation between debt and capital than the one observed. This is because our exogenous exit rate dilutes these correlations by adding a mass of firms with low capital and moderate debt. On the other hand, the correlation between capital and productivity is too high, since the optimal amount of capital to which firms converge is closely related to the productivity shock. Finally, the correlation between capital and exports, and debt and exports, is also too low in the model. This is probably coming out of our assumption of stationarity of the real exchange rate in the pre-devaluation period.

\footnotetext{
${ }^{12}$ The data was obtained from the Survey of Stocks, Capital Formation, and Productivity, conducted by Banco de Mexico. This survey includes 934 firms, from which 726 belong to the manufacturing sector. The ratio of total depreciation and total net capital stock for the firms surveyed ranges from $11 \%$ to $12 \%$ between 1989 and 2000 .
} 
Table 10 also compares the average characteristics of firms which exit in the model and in the data (i.e., firms delisted from our sample), relative to the total number of firms. As in the data, firms which exit in our model are on average small and have lower debt. Contrary to the data, however, low productivity firms exit in our model, following a standard selection argument. We are surprised not to observe such selection in the data. Exporters are also less likely to exit in the data than in the model.

Summarizing, the calibration exercise provides us with a quantitative model that reproduces some important features of the 1989-94 Mexican economy, or at least of the sample of firms that we are using. A richer model will be necessary to fully reproduce the statistical properties of the panel of firms.

\section{Experiment: The 1994-95 Devaluation}

Using our calibrated model, we perform the following experiment. Starting from the invariant distribution, which was assumed to represent the pre-1995 economy, we simulate the evolution of the economy from 1995-99 feeding the model with the observed path for the real exchange rate. This is, we start with a large depreciation of the real exchange rate followed by a progressive appreciation. Given the optimal decision rules for firm, we compute new distributions for each year, as well as aggregate statistics.

\subsection{Results}

Short run Effects Table 11 reports the aggregate levels of investment, sales, exports an foreign debt generated by the model for 1995 (normalizing their 1989-94 levels to 100) and compares them to the data ${ }^{13}$. All magnitudes are computed in units of domestic output. We reproduce fairly well the export boom and the increase in the burden of foreign debt, which gives us some confidence to assess the competitiveness and balance sheet effects on investment. The model predicts an immediate fall on investment of $21 \%$, short of the $24 \%$ drop observed in the 1995 data compared to the averages of 1989-94.

We conclude that the drop of investment in the model is largely due to a strong balance sheet effect, as the debt burden (in domestic units) increases after the real depreciation, both in the data and in our model. This effect dominates the competitiveness effect of the increase in exports, so that firms net worth decreases and, given capital market imperfections, they have to adjust decreasing investment expenditures.

\footnotetext{
${ }^{13}$ Notice that we are not using as a starting point for this comparison the actual values in the data for 1994. Given the characteristics of the experiment, we prefer to interpret the pre-devaluation situation as described by the averages of 1989-94 variables in the data, and compare the evolution of the relevant variables after the devaluation to these initial averages.
} 
Our explanation is able to account for about $85 \%$ of the drop in investment in the short run.

Medium run Effects In the medium run, the time series obtained using the benchmark model for 1995-98 are plotted in Figure 3, which also shows the evolution of the corresponding variables in the data. A simple inspection shows that the model cannot account for the sustained high levels of exports between 1996-98, when the real exchange rate appreciates, nor for the increase in domestic sales. The positive net worth effects generated by these two effects are consistent with a rapid recovery and further increase of investment in the data, which does not occur in the model.

We think that to some extent (from which we do not have a quantitative assessment, unfortunately) the actual 1995-98 path of the Mexican economy cannot be attributed to a recovery from the devaluation shock, only. This period featured other important shocks as well, as some structural reforms were implemented. One of such structural changes is the opening of the US market to Mexican imports through NAFTA, which might be responsible for the sustained export boom even after an important appreciation of the real exchange rate after 1995. Since our experiment only captures the impulse response function of the model to one large real exchange rate increase, abstracting from other shocks to the economy, we are unable to account for the path of investment in the years after the crisis.

\section{Conclusions}

We have built a model in which movements of the real exchange rate have important effects on firms' dynamics, productivity, and investment. The key channels seem to be the competitiveness effect, affecting exports, and the balance sheet effect, affecting foreign debt burden. We use the model to analyze the effects of the 1994-95 Mexican devaluation and obtain consistent results in terms of: (i) an increase in the debt burden, (ii) an increase in exports, and (iii) a decline in investment, immediately after the devaluation.

The experiment, however, has some shortcomings, especially in its ability to predict the medium term effects of the devaluation. First, we do not account for the sustained export boom in Mexico following the 1995 crisis, which are likely to be a by-product of structural reforms (as NAFTA). This boom had echoes in investment and sales in the economy, which are also underpredicted by our model. Including these reforms in the analysis is an interesting topic for future research. 


\section{References}

[1] Aguiar, M. (2002). "Devaluation, Foreign Currency Exposure and Investment: The Case of Mexico," mimeo, University of Chicago.

[2] Aghion, P., Bacchetta P., and Banerjee, A., (2000) "A Simple Model of Monetary Policy and Currency Crises", European Economic Review, 44, pp. 728-738.

[3] Bergoeing, R., Kehoe, P., Kehoe, T., Soto, R. (2002) "Decades Lost and Found: Mexico and Chile Since 1980". Federal Reserve Bank of Minneapolis Quarterly Review, Winter.

[4] Bleakley, H. and Cowan, K. (2002). "Corporate Dollar Debt and Devaluations: Much Ado About Nothing," mimeo, Massachusetts Institute of Technology.

[5] Bernanke, B. and Gertler, M. (1989). "Agency Costs, Net Worth, and Business Fluctuations," American Economic Review 79, 14-31.

[6] Caballero, R. and Krishnamurthy A. (2001). "International and Domestic Collateral Constraints in a Model of Emerging Market Crises," Journal of Monetary Economics, 48(3), 513-548.

[7] Cooley, T.F. and Quadrini, V. (2001). "Financial Markets and Firm Dynamics," American Economic Review 91, 1286-1310.

[8] Krugman, P. (1999). "Balance Sheets, The Transfer Problem and Financial Crisis" in P. Isard, A. Razin, and A. Rose eds. International Finance and Financial Crises, Essays in Honor of Robert P. Flood, Bosoton, Kluwer Academic.

[9] Pratap, S., Lobato I.N., and Somuano, A. (2003). "Debt Composition and Balance Sheet Effects of Exchange Rate Volatility in Mexico: A Firm Level Analysis", Emerging Markets Review, 450-471.

[10] Pratap, S and Rendon, S. (2003). "Firm Investment in Imperfect Capital Markets: A Structural Estimation," Review of Economic Dynamics, 513-545.

[11] Schneider, M., and A. Tornell (2001). "Balance Sheet Effects, Bailout Guarantees, and Financial Crisis". Forthcoming in Review of Economic Studies.

[12] Tauchen," G.. (1986). "Finite State Markov Chain Approximations to Univariate and Vector Autoregressions". Economic Letters, 20, 177-181.

[13] Tornell, A., Westerman, F., and L. Martinez (2004). "NAFTA and Mexico's Less than Stellar Performance". NBER Working Paper No. 10289. 


\section{A Appendix}

Proposition 1 The optimal export decision can be represented by a function $x(K, e, \theta, \eta)$. Moreover,

(i) $x=\max \left\{0, \min \left\{\left(g^{\prime}\right)^{-1}\left(\frac{1}{\eta e}\right) / \theta f(K), 1\right\}\right\}$;

(ii) $x$ is strictly decreasing in $K$ and $\theta$, if $x<1$;

(iii) $x$ is strictly increasing in $\eta$ and $e$, if $x<1$; and

(iv) $\lim _{e \rightarrow 0} x(K, e, \theta, \eta)=0$ and $\lim _{e \rightarrow+\infty} x(K, e, \theta, \eta)=1$.

Proof. The first order condition for an interior solution to the maximization in $(1)$ is $e \eta g^{\prime}(x \theta f(K))=1$, implicitly defining $x=\left(g^{\prime}\right)^{-1}\left(\frac{1}{\eta e}\right) / \theta f(K)$. Since $g$ is strictly increasing, this interior solution always satisfies the non-negativity constraint on $x$. To ensure that the upper bound on $x$ is satisfied, we impose $x=$ $\min \left\{\left(g^{\prime}\right)^{-1}\left(\frac{1}{\eta e}\right) / \theta f(K), 1\right\}$, which gives us (i). Next, it is clear that the interior solution $\left(g^{\prime}\right)^{-1}\left(\frac{1}{\eta e}\right) / \theta f(K)$ is strictly decreasing in $K$ and $\theta$, as stated in (ii). Since $g$ is strictly concave, it is also strictly increasing in $\eta$ and $e$, which proves (iii). Finally, the Inada conditions on $g$ imply that $\lim _{e \rightarrow 0}\left(g^{\prime}\right)^{-1}\left(\frac{1}{\eta e}\right)=0$ and $\lim _{e \rightarrow+\infty}\left(g^{\prime}\right)^{-1}\left(\frac{1}{\eta e}\right)=+\infty$. The limits in (iv) are then immediate from (i).

Proposition 2 The collateral function $\Pi(K, e, \theta, \eta)$ :

(i) is strictly increasing in $K$ and $\theta$,

(ii) is strictly increasing in $\eta$ and $e$. Moreover,

(iii) $\Pi(K, e, \theta, \eta) / e$ is strictly decreasing in $e$; and

(iv) $\lim _{e \rightarrow 0} \Pi(K, e, \theta, \eta) / e=+\infty$ and $\lim _{e \rightarrow+\infty} \Pi(K, e, \theta, \eta) / e=\eta g[\theta f(K)]$.

Proof. Using Proposition 1(i), we can write

$$
\Pi=e \eta g[x(K, e, \theta, \eta) \theta f(K)]+(1-x(K, e, \theta, \eta)) \theta f(K)+(1-\delta) K
$$

with $x(K, e, \theta, \eta)=\min \left\{\left(g^{\prime}\right)^{-1}\left(\frac{1}{\eta e}\right) / \theta f(K), 1\right\}$. To prove (i), (ii) and (iii), we analyze separately the cases in which the export decision is interior and the corner solution $x=1$. First, consider the case in which $x<1$, then

$$
\Pi=e \eta g\left[\left(g^{\prime}\right)^{-1}\left(\frac{1}{\eta e}\right)\right]-\left(g^{\prime}\right)^{-1}\left(\frac{1}{\eta e}\right)+\theta f(K)+(1-\delta) K .
$$

so (i) is immediate. To show (ii), we compute

$$
\begin{aligned}
\frac{\partial \Pi}{\partial e} & =e \eta g^{\prime}\left[\left(g^{\prime}\right)^{-1}\left(\frac{1}{\eta e}\right)\right] \frac{\partial\left(g^{\prime}\right)^{-1}\left(\frac{1}{\eta e}\right)}{\partial e}+\eta g\left[\left(g^{\prime}\right)^{-1}\left(\frac{1}{\eta e}\right)\right]-\frac{\partial\left(g^{\prime}\right)^{-1}\left(\frac{1}{e}\right)}{\partial e} \\
& =\eta g\left[\left(g^{\prime}\right)^{-1}\left(\frac{1}{\eta e}\right)\right]=\eta g[x(K, e, \theta, \eta) \theta f(K)]>0
\end{aligned}
$$


since $g$ is strictly increasing; similarly,

$$
\frac{\partial \Pi}{\partial \eta}=e g[x(K, e, \theta, \eta) \theta f(K)]>0
$$

We also compute

$$
\begin{aligned}
\frac{\partial \Pi / e}{\partial e}= & \eta g^{\prime}\left[\left(g^{\prime}\right)^{-1}\left(\frac{1}{\eta e}\right)\right] \frac{\partial\left(g^{\prime}\right)^{-1}\left(\frac{1}{\eta e}\right)}{\partial e}-\left(\frac{1}{e}\right) \frac{\partial\left(g^{\prime}\right)^{-1}\left(\frac{1}{\eta e}\right)}{\partial e} \\
& -\left(\frac{1}{e^{2}}\right)\left[\theta f(K)-\left(g^{\prime}\right)^{-1}\left(\frac{1}{\eta e}\right)+(1-\delta) K\right] \\
= & -\left(\frac{1}{e^{2}}\right)[(1-x(K, e, \theta, \eta)) \theta f(K)+(1-\delta) K]<0
\end{aligned}
$$

which proves (iii). Second, at the corner $x=1$,

$$
\Pi=\operatorname{e\eta g}[\theta f(K)]+(1-\delta) K
$$

clearly satisfies (i) and (ii). Moreover

$$
\frac{\Pi}{e}=\eta g[\theta f(K)]+(1-\delta) \frac{K}{e}
$$

also satisfies (iii). Finally, to prove (iv), Proposition 1(iv) implies

$$
\lim _{e \rightarrow 0} \frac{\Pi}{e}=\lim _{e \rightarrow 0} \frac{\theta f(K)+(1-\delta) K}{e}=+\infty
$$

and

$$
\lim _{e \rightarrow+\infty} \frac{\Pi}{e}=\eta g[\theta f(K)]
$$

This completes the proof.

Proposition 3 (i) If $(1+\rho) B^{\prime} \geq \Pi\left(K^{\prime}, \underline{e}, \bar{\theta}, \eta\right) / \underline{e}$, any debt contract implies $\pi=0$ and a return for the foreign lender below the risk free rate.

(ii) If $(1+\rho) B^{\prime} \leq \Pi\left(K^{\prime}, \bar{e}, \underline{\theta}, \eta\right) / \bar{e}$, the debt contract with $R^{\prime}=1+\rho$ implies $\pi=1$. This contract satisfies the zero profit condition for the foreign lender.

Proof. (i) Proposition 2(iii) implies $\Pi\left(K^{\prime}, e^{\prime}, \theta^{\prime}, \eta\right) / e^{\prime}<(1+\rho) B^{\prime}$ for all realizations of $\left(e^{\prime}, \theta^{\prime}\right) \in(\underline{e}, \bar{e}] \times[\underline{\theta}, \bar{\theta}]$. Hence, if $R^{\prime} \geq 1+\rho, \pi_{f}=0$. The lender obtains the value of the collateral $\Pi\left(K^{\prime}, e^{\prime}, \theta^{\prime}, \eta\right) / e^{\prime}$, which is less than the risk free rate. Of course, if $R^{\prime}<1+\rho$ the lender will also get less than the risk-free rate, independently of the probability of repayment. (ii) Proposition 2(iii) implies that $\Pi\left(K^{\prime}, e^{\prime}, \theta^{\prime}, \eta\right) / e^{\prime} \geq(1+\rho) B^{\prime}$ for all realizations of $\left(e^{\prime}, \theta^{\prime}\right) \in[\underline{e}, \bar{e}] \times[\underline{\theta}, \bar{\theta}]$. Hence, if $R^{\prime}=1+\rho, \pi_{f}=1$. The lender obtains with probability one $(1+\rho) B^{\prime}$, satisfying the zero profit condition (3). 
Proposition 4 Let $\theta^{\prime} \in[\underline{\theta}, \bar{\theta}]$ be such that $\Pi\left(K^{\prime}, \bar{e}, \theta^{\prime}, \eta\right)<\bar{e} R^{\prime} B^{\prime}<\Pi\left(K^{\prime}, \underline{e}, \theta^{\prime}, \eta\right)$ and define $\hat{e}\left(K^{\prime}, R^{\prime}, B^{\prime}, \theta^{\prime}, \eta\right)$ as the solution to $\Pi\left(K^{\prime}, e^{\prime}, \theta^{\prime}, \eta\right)=e^{\prime} R^{\prime} B^{\prime}$. Then

(i) there exists a unique $\underline{e}<\hat{e}<\bar{e}$;

(ii) $\Pi\left(K^{\prime}, e^{\prime}, \theta^{\prime}, \eta\right)>e^{\prime} R^{\prime} B^{\prime}, \forall e^{\prime}<\hat{e}$ and $\Pi\left(K^{\prime}, e^{\prime}, \theta^{\prime}, \eta\right)<e^{\prime} R^{\prime} B^{\prime}, \forall e^{\prime}>\hat{e}$;

(iii) $\hat{e}$ is strictly increasing in $K^{\prime}, \theta^{\prime}$, and $\eta$, and strictly decreasing in $R^{\prime}$ and $B^{\prime}$;

(iv) $\pi_{\theta^{\prime}}=F(\hat{e} \mid e) \in(0,1)$; and

(v) $\pi_{\theta^{\prime}}$ is strictly increasing in $K^{\prime}, \theta^{\prime}$, and $\eta$, and strictly decreasing in $R^{\prime}$ and $B^{\prime}$.

Proof. Consider the condition $\Pi\left(K^{\prime}, \hat{e}, \theta^{\prime}, \eta\right)=\hat{e} R^{\prime} B^{\prime}$, which can be written

$$
\frac{\Pi\left(K^{\prime}, \hat{e}, \theta^{\prime}, \eta\right)}{\hat{e}}=R^{\prime} B^{\prime}
$$

Proposition 2 establishes that the left hand side of the previous expression is decreasing in $e^{\prime}$, with $\lim _{e^{\prime} \rightarrow 0} \Pi\left(K^{\prime}, e^{\prime}, \theta^{\prime}, \eta\right) / e^{\prime}=+\infty$. Moreover, $\Pi\left(K^{\prime}, \bar{e}, \underline{\theta}, \eta\right) / \bar{e}<R^{\prime} B^{\prime}$, since from the zero profit condition (3) it is clear that $R^{\prime} \geq 1+\rho$. Therefore, there exists a unique value $0<\hat{e}<\bar{e}$ that equates the left hand side and the right hand side. To show that $\hat{e}>\underline{e}$, note that otherwise the probability of repayment would be zero, therefore the lender would lower $R^{\prime}$ until making zero-profits. This completes the proof of (i) and (ii). Proposition 2(ii) implies that as $K^{\prime}, \theta^{\prime}$, or $\eta$ increase, the left hand side shifts up, so $\hat{e}$ increases. With a similar argument, as $R^{\prime}$ or $B^{\prime}$ increase, the right hand side shifts up, so $\hat{e}$ decreases, as stated in (iii). The result in (iv) only restates (ii), given the definition of $\pi_{\theta^{\prime}}$, and implies using (iii):

$$
\begin{gathered}
\frac{\partial \pi_{\theta^{\prime}}}{\partial K^{\prime}}=f(\hat{e} \mid e) \frac{\partial \hat{e}}{\partial K^{\prime}}>0 \quad \frac{\partial \pi_{\theta^{\prime}}}{\partial \theta^{\prime}}=f(\hat{e} \mid e) \frac{\partial \hat{e}}{\partial \theta^{\prime}}>0 \\
\frac{\partial \pi_{\theta^{\prime}}}{\partial \eta}=f(\hat{e} \mid e) \frac{\partial \hat{e}}{\partial \eta}>0 \\
\frac{\partial \pi_{\theta^{\prime}}}{\partial R^{\prime}}=f(\hat{e} \mid e) \frac{\partial \hat{e}}{\partial R^{\prime}}<0 \quad \frac{\partial \pi_{\theta^{\prime}}}{\partial B^{\prime}}=f(\hat{e} \mid e) \frac{\partial \hat{e}}{\partial B^{\prime}}<0
\end{gathered}
$$

which proves $(\mathrm{v})$.

Proposition 5 Let $\Pi\left(K^{\prime}, \underline{e}, \bar{\theta}, \eta\right) / \underline{e}>(1+\rho) B^{\prime}>\Pi\left(K^{\prime}, \bar{e}, \underline{\theta}, \eta\right) / \bar{e}$ and let the equilibrium interest rate be $R^{\prime}\left(K^{\prime}, B^{\prime}, e, \theta, \eta\right)$. Then, $R^{\prime}$ is:

(i) strictly decreasing in $K^{\prime}$;

(ii) strictly increasing in $B^{\prime}$;

(iii) strictly decreasing in $\eta$.

Proof. To get the derivatives of $R^{\prime}$ with respect to $K^{\prime}$ and $B^{\prime}$ we use the implicit function theorem

$$
\frac{d R^{\prime}}{d K^{\prime}}=-\frac{\Gamma_{K^{\prime}}}{\Gamma_{R^{\prime}}} \quad \frac{d R^{\prime}}{d B^{\prime}}=-\frac{\Gamma_{B^{\prime}}}{\Gamma_{R^{\prime}}} \quad \frac{d R^{\prime}}{d \eta}=-\frac{\Gamma_{\eta}}{\Gamma_{R^{\prime}}}
$$


where $\Gamma$ is defined as in (4). Notice that

$$
\begin{aligned}
\Gamma_{R^{\prime}} & =\int_{\underline{\theta}}^{\bar{\theta}}\left\{\frac{\partial \pi_{\theta^{\prime}}}{\partial R^{\prime}} R^{\prime} B^{\prime}+\pi_{\theta^{\prime}} B^{\prime}+\frac{\partial}{\partial R^{\prime}} \int_{\widehat{e}}^{\bar{e}} \frac{\Pi\left(K^{\prime}, e^{\prime}, \theta^{\prime}, \eta\right)}{e^{\prime}} d F\left(e^{\prime} \mid e\right)\right\} d P\left(\theta^{\prime} \mid \theta\right) \\
& =\int_{\underline{\theta}}^{\bar{\theta}}\left\{f(\hat{e} \mid e) \frac{\partial \widehat{e}}{\partial R^{\prime}} R^{\prime} B^{\prime}+\pi_{\theta^{\prime}} B^{\prime}-\frac{\Pi\left(K^{\prime}, \widehat{e}, \theta^{\prime}, \eta\right)}{\widehat{e}} f(\hat{e} \mid e) \frac{\partial \widehat{e}}{\partial R^{\prime}}\right\} d P\left(\theta^{\prime} \mid \theta\right) \\
& =\int_{\underline{\theta}}^{\bar{\theta}}\left\{f(\hat{e} \mid e) \frac{\partial \widehat{e}}{\partial R^{\prime}}\left(R^{\prime} B^{\prime}-\frac{\Pi\left(K^{\prime}, \widehat{e}, \theta^{\prime}, \eta\right)}{\widehat{e}}\right)+\pi_{\theta^{\prime}} B^{\prime}\right\} d P\left(\theta^{\prime} \mid \theta\right)
\end{aligned}
$$

The first term in the brackets is zero by definition of $\widehat{e}$, so

$$
\Gamma_{R^{\prime}}=\int_{\underline{\theta}}^{\bar{\theta}} \pi_{\theta^{\prime}} B^{\prime} d P\left(\theta^{\prime} \mid \theta\right)=\pi B^{\prime}>0
$$

since, under the conditions of the proposition, $\pi \in(0,1)$. Similarly,

$$
\begin{aligned}
\Gamma_{K^{\prime}}= & \int_{\underline{\theta}}^{\bar{\theta}}\left\{\frac{\partial \pi_{\theta^{\prime}}}{\partial K^{\prime}} R^{\prime} B^{\prime}+\frac{\partial}{\partial K^{\prime}} \int_{\widehat{e}}^{\bar{e}} \frac{\Pi\left(K^{\prime}, e^{\prime}, \theta^{\prime}, \eta\right)}{e^{\prime}} d F\left(e^{\prime} \mid e\right)\right\} d P\left(\theta^{\prime} \mid \theta\right) \\
= & \int_{\underline{\theta}}^{\bar{\theta}}\left\{f(\hat{e} \mid e) \frac{\partial \widehat{e}}{\partial K^{\prime}} R^{\prime} B^{\prime}+\int_{\widehat{e}}^{\bar{e}} \frac{\partial}{\partial K^{\prime}} \frac{\Pi\left(K^{\prime}, e^{\prime}, \theta^{\prime}, \eta\right)}{e^{\prime}} d F\left(e^{\prime} \mid e\right)\right. \\
& \left.-\frac{\Pi\left(K^{\prime}, \widehat{e}, \theta^{\prime}, \eta\right)}{\widehat{e}} f(\hat{e} \mid e) \frac{\partial \widehat{e}}{\partial K^{\prime}}\right\} d P\left(\theta^{\prime} \mid \theta\right) \\
= & \int_{\underline{\theta}}^{\bar{\theta}} \int_{\widehat{e}}^{\bar{e}} \frac{\theta^{\prime} f^{\prime}\left(K^{\prime}\right)}{e^{\prime}} d F\left(e^{\prime} \mid e\right) d P\left(\theta^{\prime} \mid \theta\right) \\
= & \int_{\underline{\theta}}^{\bar{\theta}} \widehat{E}\left(\frac{1}{e^{\prime}}\right) \theta^{\prime} f^{\prime}\left(K^{\prime}\right) d P\left(\theta^{\prime} \mid \theta\right)>0
\end{aligned}
$$

where $\widehat{E}\left[\frac{1}{e^{\prime}} \mid e\right]$ represents $\int_{\widehat{e}}^{\bar{e}}\left(\frac{1}{e^{\prime}}\right) d F\left(e^{\prime} \mid e\right)$. Combining the previous results and using the implicit function theorem,

$$
\frac{d R^{\prime}}{d K^{\prime}}=-\frac{\int_{\underline{\theta}}^{\bar{\theta}} \widehat{E}\left[\frac{1}{e^{\prime}} \mid e\right] \theta^{\prime} f^{\prime}\left(K^{\prime}\right) d P\left(\theta^{\prime} \mid \theta\right)}{\pi B^{\prime}}<0
$$

This proves (i). Next, we compute

$$
\begin{aligned}
\Gamma_{B_{f}^{\prime}} & =\int_{\underline{\theta}}^{\bar{\theta}}\left\{\frac{\partial \pi_{\theta^{\prime}}}{\partial B^{\prime}} R^{\prime} B^{\prime}+\pi_{\theta^{\prime}} R^{\prime}+\frac{\partial}{\partial B^{\prime}} \int_{\widehat{e}}^{\bar{e}} \frac{\Pi\left(K^{\prime}, e^{\prime}, \theta^{\prime}, \eta\right)}{e^{\prime}} d F\left(e^{\prime} \mid e\right)\right\} d P\left(\theta^{\prime} \mid \theta\right)-(1+\rho) \\
& =\int_{\underline{\theta}}^{\bar{\theta}}\left\{f(\hat{e} \mid e) \frac{\partial \widehat{e}}{\partial B^{\prime}} R^{\prime} B^{\prime}+\pi_{\theta^{\prime}} R^{\prime}-\frac{\Pi\left(K^{\prime}, \widehat{e}, \theta, \eta\right)}{\widehat{e}} f(\hat{e} \mid e) \frac{\partial \widehat{e}}{\partial B^{\prime}}\right\} d P\left(\theta^{\prime} \mid \theta\right)-(1+\rho) \\
& =\int_{\underline{\theta}}^{\bar{\theta}} \pi_{\theta^{\prime}} R^{\prime} d P\left(\theta^{\prime} \mid \theta\right)-(1+\rho)=\pi R^{\prime}-(1+\rho)<0
\end{aligned}
$$


since otherwise $\Gamma>0$. Using again the implicit function theorem

$$
\frac{d R^{\prime}}{d B^{\prime}}=-\frac{\pi R^{\prime}-(1+\rho)}{\pi B^{\prime}}>0
$$

which completes the proof of (ii). Finally, we compute

$$
\begin{aligned}
\Gamma_{\eta}= & \int_{\underline{\theta}}^{\bar{\theta}}\left\{\frac{\partial \pi_{\theta^{\prime}}}{\partial \eta} R^{\prime} B^{\prime}+\frac{\partial}{\partial \eta} \int_{\widehat{e}}^{\bar{e}} \frac{\Pi\left(K^{\prime}, e^{\prime}, \theta^{\prime}, \eta\right)}{e^{\prime}} d F\left(e^{\prime} \mid e\right)\right\} d P\left(\theta^{\prime} \mid \theta\right) \\
= & \int_{\underline{\theta}}^{\bar{\theta}}\left\{f(\hat{e} \mid e) \frac{\partial \widehat{e}}{\partial \eta} R^{\prime} B^{\prime}+\int_{\widehat{e}}^{\bar{e}} \frac{\partial}{\partial \eta} \frac{\Pi\left(K^{\prime}, e^{\prime}, \theta^{\prime}, \eta\right)}{e^{\prime}} d F\left(e^{\prime} \mid e\right)\right. \\
& \left.-\frac{\Pi\left(K^{\prime}, \widehat{e}, \theta^{\prime}, \eta\right)}{\widehat{e}} f(\hat{e} \mid e) \frac{\partial \widehat{e}}{\partial \eta}\right\} d P\left(\theta^{\prime} \mid \theta\right) \\
= & \int_{\underline{\theta}}^{\bar{\theta}} \int_{\widehat{e}}^{\bar{e}} g\left[x\left(K^{\prime}, e^{\prime}, \theta^{\prime}, \eta\right) \theta f(K)\right] d F\left(e^{\prime} \mid e\right) d P\left(\theta^{\prime} \mid \theta\right)>0
\end{aligned}
$$

from which

$$
\frac{d R^{\prime}}{d \eta}=-\frac{\int_{\underline{\theta}}^{\bar{\theta}} \int_{\widehat{e}}^{\bar{e}} g\left[x\left(K^{\prime}, e^{\prime}, \theta^{\prime}, \eta\right) \theta f(K)\right] d F\left(e^{\prime} \mid e\right) d P\left(\theta^{\prime} \mid \theta\right)}{\pi B^{\prime}}>0
$$

completing the proof of (iii)

Proposition 6 Let $\Pi\left(K^{\prime}, \underline{e}, \bar{\theta}, \eta\right) / \underline{e}>(1+\rho) B^{\prime}>\Pi\left(K^{\prime}, \bar{e}, \underline{\theta}, \eta\right) / \bar{e}$ and let the equilibrium interest rate be $R^{\prime}\left(K^{\prime}, B^{\prime}, e, \theta\right)$. Define

$$
\varphi\left(K^{\prime} e, \theta, \eta\right) \equiv \int_{\underline{\theta}}^{\bar{\theta}}\left\{\int_{\widehat{e}}^{\bar{e}}\left(\frac{\Pi\left(K^{\prime}, e^{\prime}, \theta^{\prime}, \eta\right)}{e^{\prime}}\right) \frac{\partial f\left(e^{\prime} \mid e\right)}{\partial e} d e^{\prime}\right\} d P\left(\theta^{\prime} \mid \theta\right)
$$

Then, $R^{\prime}$ is:

(i) strictly increasing in e if $\varphi\left(K^{\prime} e, \theta, \eta\right)<0$;

(i) strictly decreasing in $e$ if $\varphi\left(K^{\prime} e, \theta, \eta\right)>0$; and

(iii) independent of e for $\varphi\left(K^{\prime} e, \theta, \eta\right)=0$.

Proof. To get the derivatives of $R^{\prime}$ with respect to e we use the implicit function theorem

$$
\frac{d R^{\prime}}{d e}=-\frac{\Gamma_{e}}{\Gamma_{R^{\prime}}}
$$


where $\Gamma$ is defined as in (4). We already showed that $\Gamma_{R^{\prime}}=\pi B^{\prime}>0$. Now,

$$
\begin{aligned}
\Gamma_{e}= & \int_{\underline{\theta}}^{\bar{\theta}}\left\{\frac{\partial \pi_{\theta^{\prime}}}{\partial e} R^{\prime} B^{\prime}+\frac{\partial}{\partial e} \int_{\widehat{e}}^{\bar{e}} \frac{\Pi\left(K^{\prime}, e^{\prime}, \theta^{\prime}, \eta\right)}{e^{\prime}} d F\left(e^{\prime} \mid e\right)\right\} d P\left(\theta^{\prime} \mid \theta\right) \\
= & \int_{\underline{\theta}}^{\bar{\theta}}\left\{f(\hat{e} \mid e) \frac{\partial \widehat{e}}{\partial e} R^{\prime} B^{\prime}+\int_{\widehat{e}}^{\bar{e}} \frac{\partial}{\partial e}\left[\frac{\Pi\left(K^{\prime}, e^{\prime}, \theta^{\prime}, \eta\right)}{e^{\prime}} f\left(e^{\prime} \mid e\right)\right] d e^{\prime}\right. \\
& \left.-\frac{\Pi\left(K^{\prime}, \widehat{e}, \theta^{\prime}, \eta\right)}{\widehat{e}} f(\hat{e} \mid e) \frac{\partial \widehat{e}}{\partial e}\right\} d P\left(\theta^{\prime} \mid \theta\right) \\
= & \int_{\underline{\theta}}^{\bar{\theta}}\left\{\int_{\widehat{e}}^{\bar{e}}\left(\frac{\Pi\left(K^{\prime}, e^{\prime}, \theta^{\prime}, \eta\right)}{e^{\prime}}\right) \frac{\partial f\left(e^{\prime} \mid e\right)}{\partial e} d e^{\prime}\right\} d P\left(\theta^{\prime} \mid \theta\right)
\end{aligned}
$$

hence

$$
\frac{d R^{\prime}}{d e}=\frac{-\int_{\underline{\theta}}^{\bar{\theta}}\left\{\int_{\widehat{e}}^{\bar{e}}\left(\frac{\Pi\left(K^{\prime}, e^{\prime}, \theta^{\prime}, \eta\right)}{e^{\prime}}\right) \frac{\partial f\left(e^{\prime} \mid e\right)}{\partial e} d e^{\prime}\right\} d P\left(\theta^{\prime} \mid \theta\right)}{\pi B^{\prime}}
$$

which proves (i), (ii), and (iii). 
Table 1: Industry Distribution of Firms

\begin{tabular}{llllllll}
\hline \hline Year & Firms & Mfg. & Transport & Services & Construction & Mining & Other \\
\hline 1989 & 98 & 0.64 & 0.01 & 0.07 & 0.09 & 0.02 & 0.16 \\
1990 & 200 & 0.61 & 0.01 & 0.11 & 0.09 & 0.02 & 0.17 \\
1991 & 224 & 0.58 & 0.01 & 0.15 & 0.08 & 0.01 & 0.17 \\
1992 & 226 & 0.54 & 0.01 & 0.17 & 0.10 & 0.02 & 0.16 \\
1993 & 221 & 0.49 & 0.03 & 0.18 & 0.12 & 0.02 & 0.16 \\
1994 & 199 & 0.48 & 0.03 & 0.20 & 0.13 & 0.02 & 0.14 \\
1995 & 182 & 0.47 & 0.03 & 0.21 & 0.13 & 0.02 & 0.14 \\
1996 & 177 & 0.46 & 0.04 & 0.24 & 0.12 & 0.02 & 0.13 \\
1997 & 168 & 0.42 & 0.04 & 0.26 & 0.11 & 0.02 & 0.15 \\
1998 & 155 & 0.41 & 0.05 & 0.27 & 0.12 & 0.02 & 0.14 \\
1999 & 137 & 0.41 & 0.05 & 0.28 & 0.12 & 0.02 & 0.12 \\
2000 & 113 & 0.45 & 0.04 & 0.27 & 0.12 & 0.02 & 0.10 \\
\hline \hline
\end{tabular}


Table 2: Averages of Key Ratios 1989-1994

\begin{tabular}{rrrrrrrr}
\hline \hline Year & $\mathrm{e}$ & $\frac{\text { Capital }}{\text { Sales }}$ & $\frac{\text { Investment }}{\text { Sales }}$ & $\frac{\text { Exports }}{\text { Sales }}$ & $\frac{\text { STDebt }}{\text { Exports }}$ & $\frac{\text { TotalDebt }}{\text { Exports }}$ & $\frac{F C}{\text { Liab }}$ \\
\hline 1989 & 4.644 & 1.512 & 0.124 & 0.136 & 0.740 & 1.421 & 0.192 \\
1990 & 4.612 & 1.293 & 0.140 & 0.126 & 1.125 & 1.824 & 0.150 \\
1991 & 4.220 & 1.315 & 0.108 & 0.104 & 1.552 & 2.479 & 0.120 \\
1992 & 3.961 & 1.243 & 0.144 & 0.085 & 1.492 & 2.867 & 0.105 \\
1993 & 3.437 & 1.262 & 0.127 & 0.081 & 1.563 & 3.792 & 0.105 \\
1994 & 3.503 & 1.167 & 0.158 & 0.103 & 1.769 & 4.163 & 0.076 \\
Avg. & & 1.277 & 0.135 & 0.103 & 1.403 & 2.812 & 0.113 \\
\hline \hline
\end{tabular}

Note: $\frac{F C}{L i a b}$ is the ratio of total interest payments to total liabilities. ST Debt refers to short term debt.

Table 3: Correlations Between Key Variables, 1989-1994

\begin{tabular}{ll}
\hline \hline Correlation Between & \\
\hline Capital and Short Term Debt & 0.664 \\
Capital and Total Debt & 0.748 \\
Capital and Exports & 0.641 \\
Capital and Financing Costs* & -0.349 \\
Short Term Debt and Exports & 0.659 \\
Total Debt and Exports & 0.641 \\
Total Debt and Financing Costs $\dagger$ & 0.513 \\
\hline \hline
\end{tabular}

* Refers to partial correlation, keeping total debt Constant. $\dagger$ refers to partial correlation keeping total capital constant. In both cases financing costs are defined as the ratio of total interest paid to total liabilities. 
Table 4: Joint Distributions of Total Debt, Capital and Exports, 1989-1994

\begin{tabular}{lccc}
\hline \hline Total Debt & Capital & Exports & Sales \\
\hline 0 & 0.014 & 0.001 & 0.032 \\
0 to 25th percentile & 0.012 & 0.002 & 0.012 \\
25th to 50th percentile & 0.082 & 0.019 & 0.137 \\
50th to 75th percentile & 0.154 & 0.103 & 0.174 \\
Above 75th percentile & 0.739 & 0.875 & 0.645 \\
\hline \hline
\end{tabular}

Figures represent proportions of capital, exports and sales of each category of firms in total capital, exports and sales respectively for the period 1989 to 1994.

Table 5: Averages of Key Ratios 1994-2000

\begin{tabular}{rrrrrrrr}
\hline \hline Year & $\mathrm{e}$ & $\frac{\text { Capital }}{\text { Sales }}$ & $\frac{\text { Investment }}{\text { Sales }}$ & $\frac{\text { Exports }}{\text { Sales }}$ & $\frac{\text { STDebt }}{\text { Exports }}$ & $\frac{\text { TotalDebt }}{\text { Exports }}$ & $\frac{F C}{\text { Liab }}$ \\
\hline 1994 & 3.503 & 1.167 & 0.158 & 0.103 & 1.769 & 4.163 & 0.076 \\
1995 & 5.409 & 1.355 & 0.100 & 0.202 & 1.229 & 2.527 & 0.165 \\
1996 & 4.754 & 1.219 & 0.119 & 0.197 & 0.966 & 2.059 & 0.138 \\
1997 & 3.964 & 1.112 & 0.073 & 0.199 & 0.697 & 2.059 & 0.103 \\
1998 & 3.909 & 1.106 & 0.132 & 0.204 & 0.741 & 1.853 & 0.096 \\
1999 & 3.588 & 1.129 & 0.072 & 0.184 & 0.710 & 1.881 & 0.085 \\
2000 & 3.180 & 0.880 & 0.069 & 0.245 & 0.570 & 1.323 & 0.078 \\
\hline \hline
\end{tabular}

Note: $\frac{F C}{L i a b}$ is the ratio of total interest payments to total liabilities. ST Debt refers to short term debt. 
Table 6: Changes in Average Magnitudes, 1994=100

\begin{tabular}{rrrrrrr}
\hline \hline Year & Capital & Investment & Sales & Exports & ST Debt & Total Debt \\
\hline 1994 & 100.000 & 100.000 & 100.000 & 100.000 & 100.000 & 100.000 \\
1995 & 111.683 & 61.842 & 98.239 & 192.244 & 133.523 & 116.693 \\
1996 & 110.380 & 78.449 & 104.699 & 199.858 & 109.146 & 98.850 \\
1997 & 114.496 & 55.352 & 119.031 & 229.985 & 90.619 & 113.721 \\
1998 & 124.469 & 106.283 & 127.716 & 253.283 & 106.048 & 112.743 \\
1999 & 125.251 & 58.891 & 130.103 & 219.336 & 88.041 & 99.109 \\
2000 & 122.672 & 76.509 & 175.388 & 354.541 & 113.449 & 111.794 \\
\hline \hline
\end{tabular}

Table 7: Balance Sheet Effects

\begin{tabular}{l|l|l}
\hline \hline & Exports Below Median & Exports Above Median \\
\hline Debt Below Median & 17.592 & 7.146 \\
& $(16.267)$ & $(5.535)$ \\
\hline Debt Above Median & 217.979 & 226.709 \\
& $(108.943)$ & $(201.616)$ \\
\hline \hline
\end{tabular}

The top figure in each cell represents the average investment of firms in each category between 1989 and 1994. The lower figure represents the average investment between 1995 and 2000. All figures are in millions of 1994 pesos. Debt refers to total debt. 
Table 8: Sample Statistics as a Percentage of Macro Aggregates

\begin{tabular}{rrrr}
\hline \hline Year & Investment & Dollar Debt & Exports \\
\hline 1989 & 8.1 & 53.0 & 13.0 \\
1990 & 14.0 & 67.0 & 20.4 \\
1991 & 10.3 & 68.0 & 18.2 \\
1992 & 13.4 & 69.0 & 15.6 \\
1993 & 12.9 & 83.0 & 15.3 \\
1994 & 15.9 & 87.0 & 17.6 \\
1995 & 12.0 & 69.0 & 18.3 \\
1996 & 12.5 & 60.0 & 15.8 \\
1997 & 6.5 & 71.0 & 16.9 \\
1998 & 10.6 & 43.0 & 14.6 \\
1999 & 5.0 & 31.0 & 11.9 \\
2000 & 5.0 & 32.0 & 17.0 \\
\hline \hline
\end{tabular}

Source: Banco de Mexico. Exports do not include petroleum. Dollar debt refers to total private sector dollar debt.

Table 9: Calibration of Benchmark Model

\begin{tabular}{||lcc|cc||}
\hline Target & Data (89-94) & Model & Parameter & Value \\
\hline 1. Capital/Sales & 1.27 & 1.31 & $\alpha$ & 0.36 \\
2. Investment/Sales & 0.14 & 0.14 & $\delta$ & 0.11 \\
3. Exports/Sales & 0.10 & 0.09 & $\xi$ & 0.63 \\
4. Debt/Exports & 2.25 & 2.19 & $\phi$ & 55.00 \\
5. Exit rate & 0.11 & 0.11 & $\lambda$ & 0.06 \\
\hline
\end{tabular}


Table 10: Other Statistics for Benchmark Model

\begin{tabular}{||l|cc||}
\hline Statistic & Data (89-94) & Model \\
\hline 1. Correlation betweeen Capital and: & 0.75 & 0.44 \\
$\quad$ - Foreign debt & 0.49 & 0.87 \\
- Productivity $(\theta)$ & 0.64 & 0.12 \\
- Exports & 0.36 & 0.14 \\
2. Correlation betweeen debt and: & 0.64 & 0.24 \\
$\quad$ - Productivity $(\theta)$ & & \\
- Exports & 0.51 & 0.52 \\
3. Statistics for exits relative to total: & 0.22 & 0.59 \\
- Avg. capital & 1.60 & 0.54 \\
- Avg. debt & 0.10 & 0.72 \\
- Avg. productivity $(\theta)$ & & \\
- Avg. export type $(\eta)$ &
\end{tabular}

Table 11: Results of Devaluation Experiment

\begin{tabular}{||l|cc|cc||}
\hline & $89-94$ & & 1995 & \\
& Data & Model & Data & Model \\
\hline Investment & 100.0 & 100.0 & 86.0 & 88.7 \\
Total Sales & 100.0 & 100.0 & 116.0 & 105.7 \\
Domestic Sales & 100.0 & 100.0 & 104.0 & 94.0 \\
Exports & 100.0 & 100.0 & 229.0 & 222.5 \\
Foreign Debt & 100.0 & 100.0 & 163.0 & 151.1 \\
\hline
\end{tabular}




\section{Figure 1: Optimal Export Decision}

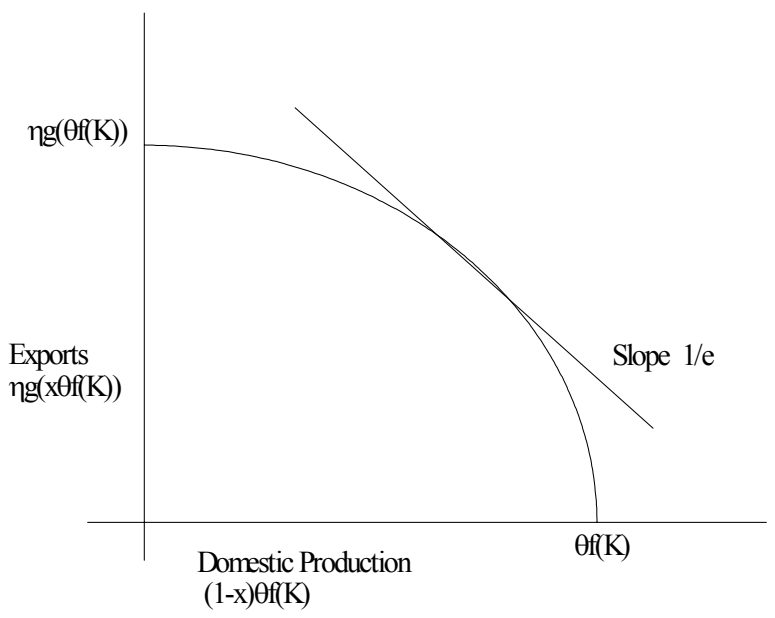

Figure 2: Balance Sheet Effects of a Real Depreciation

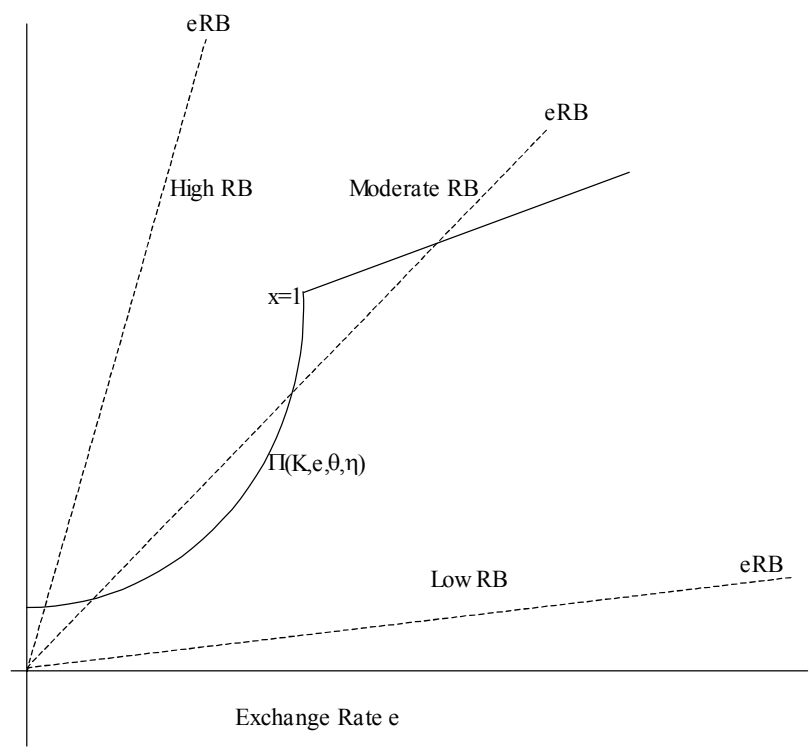


Figure 3: Medium-run Results of the Devaluation Experiment
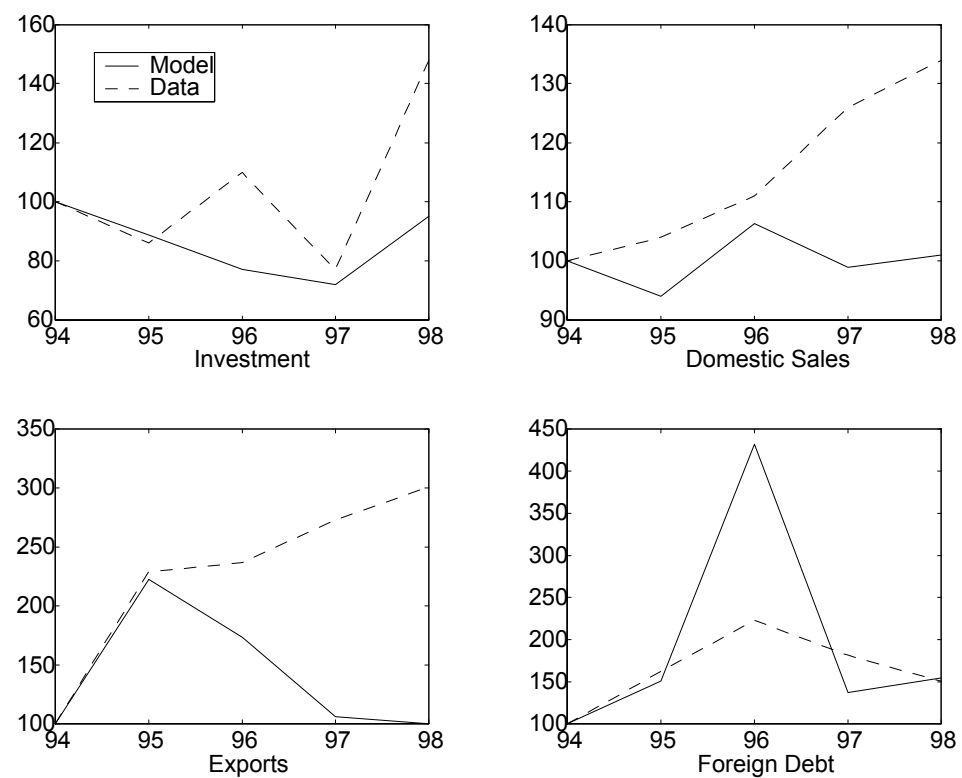